\title{
Induction of targeted, heritable mutations in barley and Brassica oleracea using RNA-guided Cas9 nuclease
}

\author{
Tom Lawrenson ${ }^{1 \dagger}$, Oluwaseyi Shorinola ${ }^{1 \dagger}$, Nicola Stacey ${ }^{1}$, Chengdao Li $^{2}$, Lars Østergaard ${ }^{1}$, Nicola Patron $^{3}$, \\ Cristobal Uauy ${ }^{1 *}$ and Wendy Harwood ${ }^{1 *}$
}

\begin{abstract}
Background: The RNA-guided Cas9 system represents a flexible approach for genome editing in plants. This method can create specific mutations that knock-out or alter target gene function. It provides a valuable tool for plant research and offers opportunities for crop improvement.

Results: We investigate the use and target specificity requirements of RNA-guided Cas9 genome editing in barley (Hordeum vulgare) and Brassica oleracea by targeting multicopy genes. In barley, we target two copies of HvPM19 and observe Cas9-induced mutations in the first generation of $23 \%$ and $10 \%$ of the lines, respectively. In $B$. oleracea, targeting of Bo/C.GA4.a leads to Cas9-induced mutations in $10 \%$ of first generation plants screened. In addition, a phenotypic screen identifies $T_{0}$ plants with the expected dwarf phenotype associated with knock-out of the target gene. In both barley and B. oleracea stable Cas9-induced mutations are transmitted to $T_{2}$ plants independently of the T-DNA construct. We observe off-target activity in both species, despite the presence of at least one mismatch between the single guide RNA and the non-target gene sequences. In barley, a transgene-free plant has concurrent mutations in the target and non-target copies of HVPM19.

Conclusions: We demonstrate the use of RNA-guided Cas9 to generate mutations in target genes of both barley and $B$. oleracea and show stable transmission of these mutations thus establishing the potential for rapid characterisation of gene function in these species. In addition, the off-target effects reported offer both potential difficulties and specific opportunities to target members of multigene families in crops.
\end{abstract}

Keywords: Genome editing, CRISPR/Cas9, Barley, Brassica, PM19, GA4, Crops, Mutations, Breeding, Off-target

\section{Background}

Genetic modification is a key research tool for advancing knowledge of gene function as well as allowing the development of crops with valuable traits. Genetic modification enables the introduction of genes of interest or the reduction in expression of endogenous genes (RNAi approaches) through the insertion of transgenic sequences at random locations within the plant genome. Genetic modification technologies have advanced substantially over the past 30 years, but more recently, a series of exciting developments offer significant opportunities for the

\footnotetext{
* Correspondence: cristobal.uauy@jic.ac.uk; wendy.harwood@jic.ac.uk

${ }^{\dagger}$ Equal contributors

'John Innes Centre, Norwich Research Park, Colney NR4 7UH, UK

Full list of author information is available at the end of the article
}

analyses of plant genomes, as well as having applications in crop improvement [1]. These approaches, collectively called genome editing, provide the opportunity to make precise changes at specific genomic locations. Genome editing may be used to induce gene insertions, gene replacements, or insertions or deletions that disrupt the function of a specific gene [2]. This latter application, leading to knock-out of target genes, has enormous benefits for research in plants, especially in crops that lack genetic resources such as knock-out libraries.

Genome editing requires a site-directed nuclease to introduce one or more breaks in the DNA at the target locus. The cell's endogenous DNA repair mechanisms repair these breaks; imperfect repair can produce mutations or deletions in the genes of interest. To generate
C Biomed Central international License (http://creativecommons.org/licenses/by/4.0/), which permits unrestricted use, distribution, and reproduction in any medium, provided you give appropriate credit to the original author(s) and the source, provide a link to the Creative Commons license, and indicate if changes were made. The Creative Commons Public Domain Dedication waiver (http://creativecommons.org/publicdomain/zero/1.0/) applies to the data made available in this article, unless otherwise stated. 
site-specific breaks, different approaches have employed different combinations of nucleases fused to programmable DNA binding domains including Zinc Finger Nucleases (ZFNs) and Transcription-Activator Like Effector Nucleases (TALENs). More recently, the Cas9 protein associated with Type II Clustered Regulatory Interspaced Short Palindromic Repeats (CRISPR) found in bacteria has been repurposed for genome editing in eukaryotes [3, 4]. The RNA-guided Cas9 system uses a small non-coding RNA, known as the single guide RNA (sgRNA), to direct the Cas9 nuclease to the DNA target of interest. Being small and easy to reprogram, this offers a flexible, easy-toimplement and relatively cheap method for genome editing [5]. The first applications of RNA-guided Cas9 in plants were described in 2013 [6-8] using transient systems. Inheritance of induced mutations in progeny plants was demonstrated for the first time in Arabidopsis by Feng et al. [9] and heritable changes have also been shown in rice $[10,11]$. In wheat (Triticum aestivum), RNAguided Cas9 has been used to mutate a single homoeologue of the mildew resistance locus $M L O$ in stable $\mathrm{T}_{0}$ transgenic plants although no information was provided regarding the inheritance of the mutant alleles [12].

Very few studies have described the inheritance of RNA-guided Cas9-induced mutations and questions remain regarding its efficiency, especially in crop plants. In addition, the frequency with which the nuclease induces mutations in unintended targets (known as off-targets) has yet to be extensively investigated across plant species. The aim of this study was therefore to use RNA-guided Cas9 for targeted mutagenesis in both monocotyledonous and dicotyledonous crop species, demonstrating for the first time its application in both barley (Hordeum vulgare) and Brassica oleracea. In addition, we aimed to assess the efficiency of mutagenesis and test whether off-target effects occurred.

Arabidopsis GA4 is involved in the gibberellin biosynthesis pathway and GA4 loss-of-function mutants have dwarf stature and reduced fruit dehiscence [13, 14]. Since plant architecture and seed dispersal are important targets for crop improvement in Brassicas, we tested the effect of mutating GA4 orthologues in B. oleracea. In barley, we chose HvPM19 as our target. HvPM19 encodes an ABA-inducible plasma membrane protein [15], which in wheat acts as a positive regulator of grain dormancy [16], an important agronomic trait in cereals.

Here we demonstrate the successful use of RNAguided Cas9 genome editing to knockout the function of target genes in both barley and B. oleracea. We show transmission of the mutation to progeny plants in both species and we demonstrate the segregation of the transgenic locus (encoding the nuclease and sgRNA) from the mutation, resulting in transgene-free plants that contain the desired mutation.

\section{Results and discussion}

\section{RNA-guided Cas9-induced genome editing in barley}

We investigated the use and target specificity requirements of RNA-guided Cas9 genome editing in barley by focusing on a multi-copy gene. We selected HvPM19, which is present as four copies within a single barley BAC clone from the cultivar 'Morex' (HvPM19-1 to HvPM19-4; Fig. 1a). Relative to HvPM19-1, the HvPM19-2, HvPM19-3 and HvPM19-4 loci have sequence identities of $89.8 \%, 89.5 \%$ and $88.6 \%$, respectively, whereas HvPM19-3 and HvPM19-4 have greater sequence identity to HvPM19-2 (98.4 \% and $99.6 \%$ ). This suggests that HvPM19-1 was involved in the more ancestral duplication event and that there was a series of very recent duplication events between HvPM19-2, HvPM19-3 and HvPM19-4.

We independently targeted two ancestral HvPM19 gene copies (HvPM19-1 and HvPM19-3) in the spring barley cultivar 'Golden Promise' which is amenable to Agrobacterium-mediated transformation. We were able to amplify HvPM19-4 from Golden Promise, but unable to amplify $H v P M 19-2$ suggesting that this cultivar lacks this copy of HvPM19. Two binary constructs, sgRNAHvPM19-1, referred to as pPM19-1 and sgRNAHvPM19-3, referred to as pPM19-3 (Fig. 2a), were designed to independently target HvPM19-1 and HvPM19-3, respectively. The 20 base-pair target sequence in pPM19-1 has a single nucleotide mismatch with each of the corresponding sequences in HvPM19-3 and HvPM19-4, while the target sequence in pPM19-3 has three mismatches with HvPM19-1 and one mismatch with HvPM19-4 (Fig. 3a).

The two constructs were independently transformed into immature barley embryos to generate 28 and 20 independent transgenic lines for pPM19-1 and pPM19-3, respectively. $T_{0}$ regenerated plantlets were screened for mutations using a restriction digest/PCR assay. We detected deletions in HvPM19-1 in three out of 13 pPM19-1 $\mathrm{T}_{0}$ lines screened $\left(\mathrm{T}_{0}-181, \mathrm{~T}_{0}-122\right.$ and $\left.\mathrm{T}_{0}-191\right)$. Similarly, out of the 10 pPM19-3 $\mathrm{T}_{0}$ plantlets screened, one line $\left(\mathrm{T}_{0}-211\right)$ showed an insertion in HvPM19-3. Therefore, the frequency of Cas9-induced mutations in the first generation was $23 \%$ for pPM19- 1 and $10 \%$ for pPM19-3. These mutation frequencies are comparable to those reported in stable $\mathrm{T}_{0}$ transformants from other monocotyledonous species such as wheat [12], rice (Oryza sativa; reviewed in [17]) and sorghum (Sorghum bicolor; [18]).

As is characteristic of Cas9-induced mutations [3, 4, 19], all the insertions or deletions (in-dels) detected were at the 3' end of the target region, 3 or 4 bp upstream of the Protospacer Adjacent Motif (PAM; Additional file 1). In the $\mathrm{T}_{0}$ plants, we detected in-dels only after enriching for the mutation by the restriction digest/PCR assay presumably because only a small proportion of the cells had 


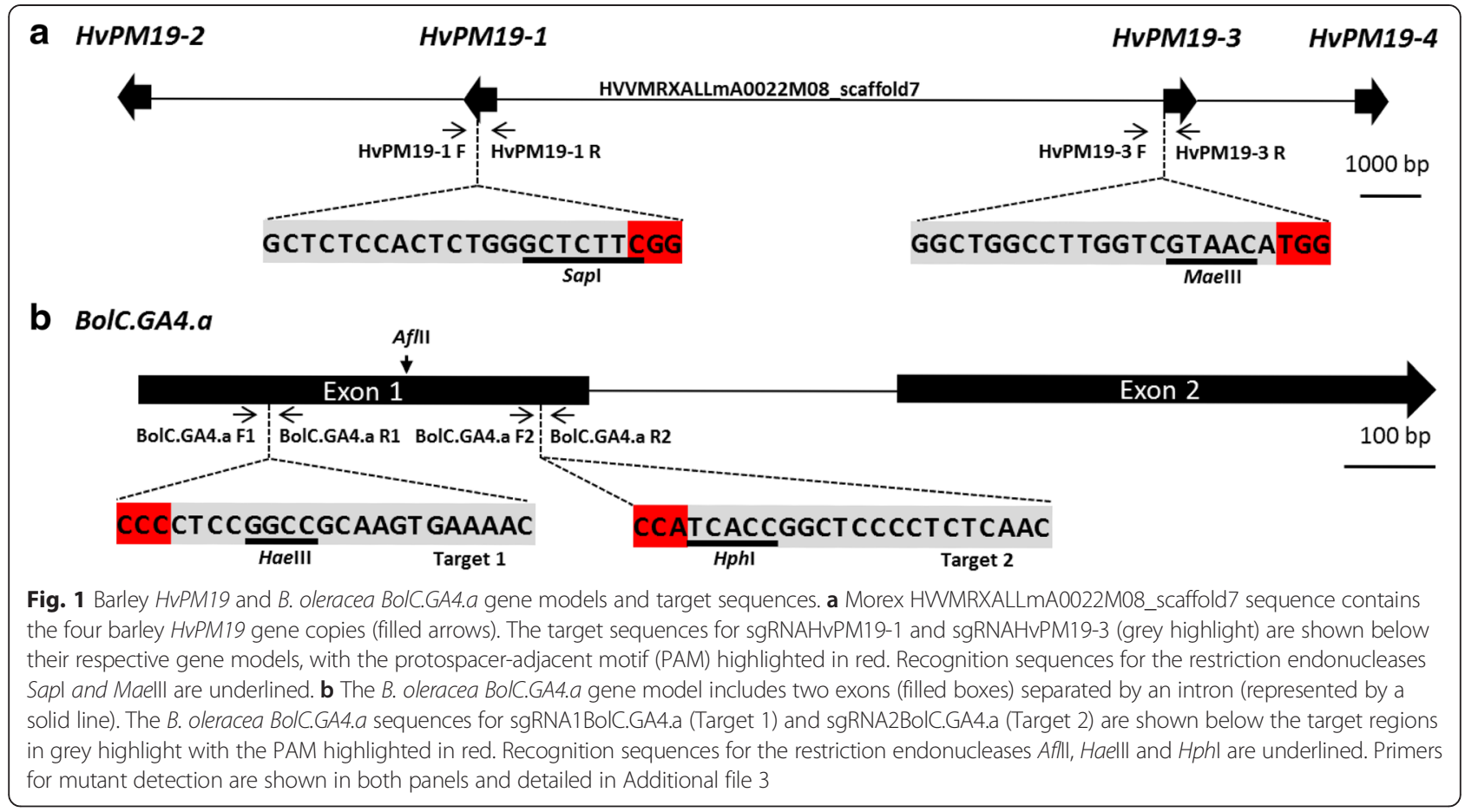

been mutated at the time of sampling. To further characterise the events, we measured T-DNA copy number in the $T_{0}$ lines and found that $T_{0^{-}} 181, T_{0^{-}}-191$ and $T_{0^{-}}$ 211 each contained a single copy of the T-DNA whereas $\mathrm{T}_{0}$-122 contained two copies.

On-target and off-target activity of RNA-guided Cas9 in $\mathrm{T}_{1}$ transgenic barley plants

Next, we examined the $T_{1}$ progenies of $T_{0}-181, T_{0}-122$, $\mathrm{T}_{0}-191$ and $\mathrm{T}_{0}-211$. Twenty out of $93 \mathrm{~T}_{1}$ progenies of $\mathrm{T}_{0}-181$ contained in-dels in the target HvPM19-1 sequence as determined by Sanger sequencing. Of these, two were homozygous and 18 were heterozygous mutants determined by the presence of double peaks in the sequencing chromatogram beginning from the site of the in-del. For $\mathrm{T}_{0}-122$, only six out of $95 \mathrm{~T}_{1}$ progenies had in-dels in the target HvPM19-1 sequence, with all being heterozygous mutations. This represents mutation frequencies of $22 \%$ in $\mathrm{T}_{0}-181$ and $6 \%$ in $\mathrm{T}_{0}-122$ progenies. For line $\mathrm{T}_{0}-211$, which showed Cas9 activity for HvPM19-3, we detected four mutant plants out of $76 \mathrm{~T}_{1}$ progenies tested, all of which had heterozygous

\section{a LB-P-CaMv35S Hptll T-CaMv35s - P-ZmUbi SpCas9:NLS T-AtNo Binary vectors sgRNAHvPM19-1 and sgRNAHvPM19-3 \\ b

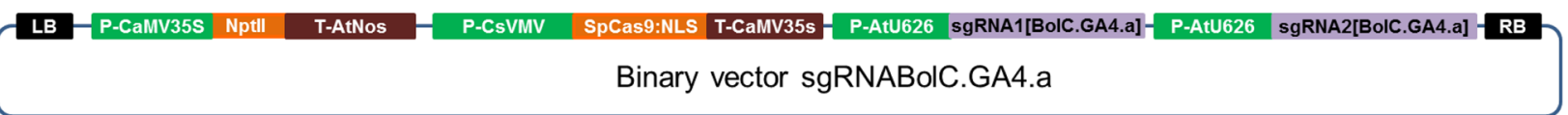

Fig. 2 Schematic of binary plasmid vectors delivered to barley and B. oleracea. Transcription units were assembled into the binary plasmid backbone pAGM4723 or pAGM8031 using Golden Gate Modular Cloning. a The barley constructs, sgRNAHvPM19-1 and sgRNAHvPM19-3 house a hygromycin resistance cassette consisting of the hygromycin phosphotransferase coding sequence (hptll) driven and terminated by the 35 s promoter (P-CaMV35s) and terminator (T-CaMV35s) from Cauliflower mosaic virus; a Cas9 expression cassette consisting of sequence encoding Cas9 from Streptococcus pyogenies with a carboxy-terminal nuclear-localization signal from Simian vacuolating virus 40 (SpCas9:NLS) driven by a ubiquitin promoter from Zea mays (P-ZmUbi) and terminated by a nopaline synthase terminator from Agrobacterium tumefaciens (T-AtNos); and single guide RNA (sgRNAHvPM19-1 or sgRNAHvPM19-3) driven by a Triticum aestivum U6 promoter (P-TaU6). b The Brassica construct, sgRNABolC.GA4.a, houses a kanamycin resistance cassette consisting of the neomycin phosphotransferase coding sequence (npt/) driven and terminated by P-CaMV35S and T-AtNos; SpCas9:NLS driven by a constitutive promoter from Cassava Vein Mosaic Virus (P-CsVMV) and a tandem pair of single guide RNAs (sgRNA1BolC.GA4.a and sgRNA2BolC.GA4.a) driven by the U626 promoter from Arabidopsis (P-AtU626) 


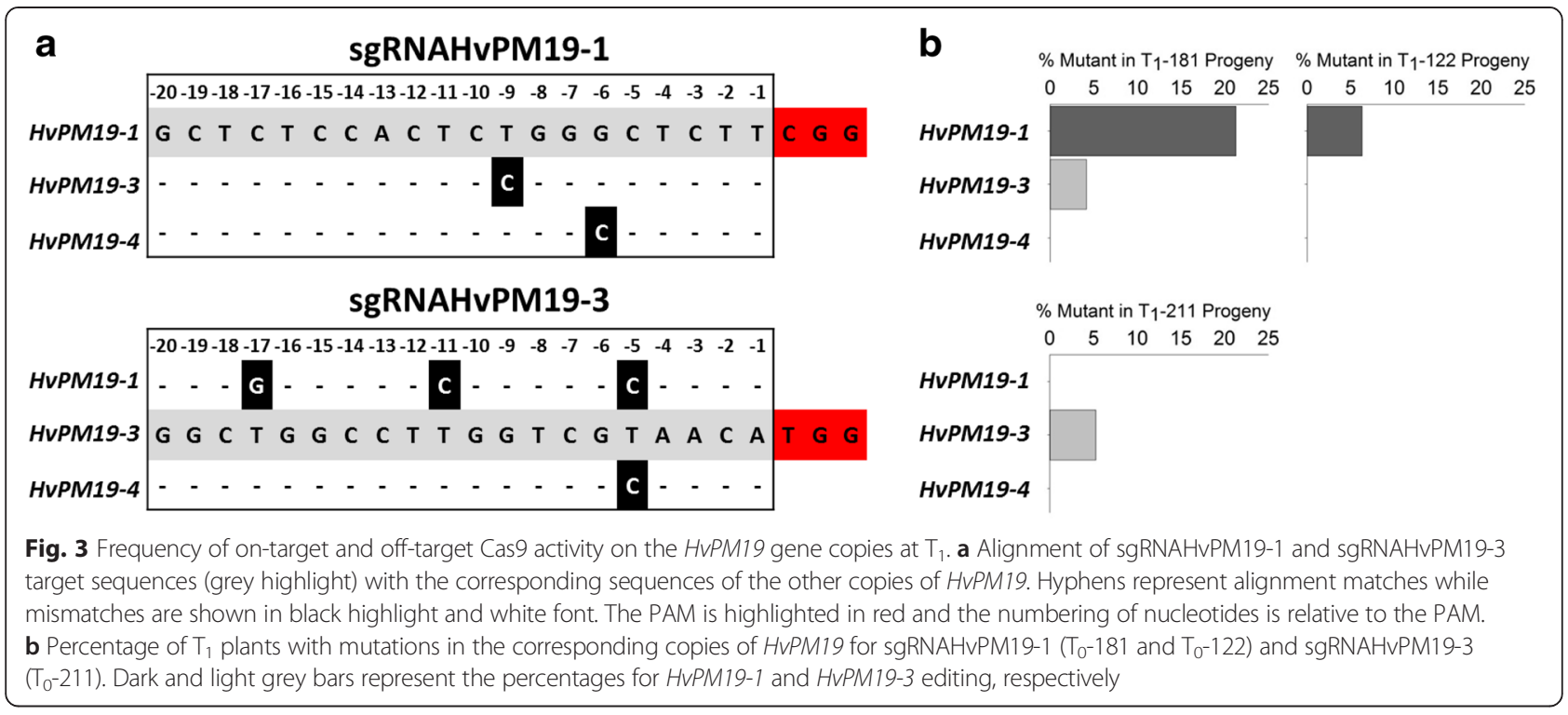

mutations (mutation frequency of $5 \%$ ). Line $\mathrm{T}_{0}-191$ showed mutations in seven out of $90 \mathrm{~T}_{1}$ plants, but was not analysed further. As in the $\mathrm{T}_{0}$ generation, all the indels were observed to occur in the 3-4 bp adjacent to the PAM. All the $\mathrm{T}_{1}$ plants with Cas9-induced mutations retained their corresponding T-DNA construct, while there was segregation in the non-mutated $T_{1}$ plants. This indicated that the mutations could still be the product of sgRNA/Cas9 expression in somatic cells rather than due to germline inheritance.

To assess the specificity of the T-DNA constructs, we sequenced HvPM19-3 and HvPM19-4 in the progenies of $\mathrm{T}_{0}-181$ and $\mathrm{T}_{0}-122$ (designed to target HvPM19-1). We found no off-target activity in the $\mathrm{T}_{1}$ progenies of $\mathrm{T}_{0}-122$; whereas three $\mathrm{T}_{0}-181$ progeny from 72 tested (4.2\%) had off-target activity on HvPM19-3 (Fig. 3b). By contrast, we observed no off-target activity on $H v P M 19-1$ and $H v P M 19-4$ in the $73 \mathrm{~T}_{1}$ progenies of $\mathrm{T}_{0}-211$ that contained the T-DNA designed to target HvPM19-3.

\section{Cas9-induced mutations are stably transmitted to $\mathbf{T}_{2}$} barley plants independently of the T-DNA construct

The mutation in the target gene theoretically should segregate independently of the T-DNA that encodes the nuclease and sgRNA. We observed complete co-segregation of the Cas9-induced mutations with the T-DNA construct in the $T_{1}$ transgenic lines. We therefore tested the $T_{2}$ progenies of several $\mathrm{T}_{1}$ lines to determine if the mutations could be stably inherited and segregate independently from the T-DNA construct. We screened for the presence of the T-DNA through PCR and qPCR assays and determined the mutation status in the $T_{2}$ progenies of $T_{1}-181$, $T_{1}-122$ and $T_{1}-211$ lines $\left(T_{1}\right.$ mutant lines originating from the corresponding $\mathrm{T}_{0}$ lines; Table 1 ). The T-DNA segregated in the progeny of some, but not all, of these $T_{1}$ lines. Segregation of pPM19-1 was detected in 11 out of $19 \mathrm{~T}_{1}$-181 lines, whereas pPM19-1 segregated in the progeny of four out of six $\mathrm{T}_{1}-122$ lines. However, only one out of three $T_{1}-211$ lines tested showed segregation of the pPM19-3 construct. A 3:1 presence:absence ratio was confirmed using a $\chi^{2}$ test in all progenies in which the T-DNA segregated $(P>0.44$ or higher).

We next sequenced $H v P M 19-1$ and $H v P M 19-3$ from all $45 \mathrm{~T}_{2}$ plants that had not inherited the T-DNA. In these plants, we detected mutations in HvPM19-1 in $15 \mathrm{~T}_{2}$ progenies originating from seven independent $\mathrm{T}_{1}-181$ lines and seven $\mathrm{T}_{2}$ progenies originating from three independent $\mathrm{T}_{1}$-122 lines (Table 1). A single progeny of $\mathrm{T}_{1}$-181_H2 showed an off-target mutation in $H v P M 19-3$ in addition to the on-target $H v P M 19-1$ mutation. Interestingly, $\mathrm{T}_{1}-181 \_\mathrm{H} 2$ is one of the three $\mathrm{T}_{0}$-181 lines that showed off-target activity of pPM191 in the $T_{1}$ generation. For pPM19-3, we did not detect mutations in HvPM19-3 (and HvPM19-1) in the absence of the T-DNA in the progenies of any of the $\mathrm{T}_{1}-211$ lines.

We found that the mutations detected in the $T_{2}$ progenies matched those observed in the corresponding $\mathrm{T}_{1}$ parent in all cases examined. For instance, the homozygous 1-bp deletion observed in line $\mathrm{T}_{1}-181$ _E1 was also present in all its $\mathrm{T}_{2}$ progenies that segregated away from the T-DNA construct (Table 1; Fig. 4a). Likewise, a range of mutations found in heterozygous $\mathrm{T}_{1}$ plants were also identified in homozygous $\mathrm{T}_{2}$ individuals in the absence of the T-DNA construct (Fig. 4b). Taken together, the $\mathrm{T}_{1}$ and $\mathrm{T}_{2}$ sequence data from six lines, originating from two independent $T_{0}$ events $\left(T_{0}-181\right.$ and $\left.T_{0}-122\right)$, provide strong evidence of stable germline transmission 
Table 1 Summary of transgenerational RNA-guided Cas9 activity and segregation in barley

\begin{tabular}{|c|c|c|c|c|c|c|}
\hline T-DNA Construct & $T_{0}$ line & $\mathrm{T}_{1}$ mutation type & $T_{1}$ line & $\begin{array}{l}\text { Number of } \mathrm{T}_{2} \text { plants } \\
\text { screened for T-DNA }\end{array}$ & $\begin{array}{l}\text { Plants without } \\
\text { T-DNA }\end{array}$ & $\begin{array}{l}\text { Plants without T-DNA and with (homozygous/ } \\
\text { heterozygous) mutations }{ }^{a}\end{array}$ \\
\hline \multirow[t]{25}{*}{ pPM19-1 } & \multirow[t]{19}{*}{$\mathrm{T}_{0}-181$} & \multirow[t]{2}{*}{ Homozygous } & $\mathrm{T}_{1}-181 \_\mathrm{B} 5$ & 4 & 0 & - \\
\hline & & & $\mathrm{T}_{1}-181 \_\mathrm{E} 1$ & 12 & 5 & $5 / 0$ \\
\hline & & \multirow[t]{17}{*}{ Heterozygous } & $\mathrm{T}_{1}-181 \_\mathrm{A} 11$ & 12 & 3 & $1 / 1$ \\
\hline & & & $\mathrm{T}_{1}-181 \_\mathrm{B} 1$ & 8 & 2 & $0 / 0$ \\
\hline & & & $\mathrm{T}_{1}-181 \_\mathrm{B} 8$ & 11 & 0 & - \\
\hline & & & $\mathrm{T}_{1}-181 \_\mathrm{C} 1$ & 9 & 0 & - \\
\hline & & & $\mathrm{T}_{1}-181 \_\mathrm{C} 12$ & 1 & 0 & - \\
\hline & & & $\mathrm{T}_{1}-181 \_\mathrm{C} 3$ & 12 & 0 & - \\
\hline & & & $\mathrm{T}_{1}-181 \_\mathrm{C} 4$ & 12 & 1 & $0 / 0$ \\
\hline & & & $\mathrm{T}_{1}-181 \_\mathrm{C} 9$ & 11 & 1 & $0 / 1$ \\
\hline & & & $\mathrm{T}_{1}-181 \_\mathrm{D} 11$ & 12 & 4 & $1 / 1$ \\
\hline & & & $\mathrm{T}_{1}-181 \_\mathrm{D} 2$ & 12 & 3 & $2 / 0$ \\
\hline & & & T1-181_D9 & 2 & 0 & - \\
\hline & & & $\mathrm{T}_{1}-181 \_\mathrm{E} 4$ & 12 & 0 & - \\
\hline & & & $\mathrm{T}_{1}-181 \_\mathrm{G} 4$ & 11 & 3 & $0 / 1$ \\
\hline & & & T1-181_G5 & 12 & 1 & $0 / 0$ \\
\hline & & & $\mathrm{T}_{1}-181 \_\mathrm{H} 2$ & 12 & 3 & $1 / 1$ \\
\hline & & & $\mathrm{T}_{1}-181 \_\mathrm{H} 5$ & 12 & 0 & - \\
\hline & & & $\mathrm{T}_{1}-181 \_\mathrm{H} 9$ & 12 & 4 & $0 / 0$ \\
\hline & \multirow[t]{6}{*}{$T_{0}-122$} & \multirow[t]{6}{*}{ Heterozygous } & $\mathrm{T}_{1}-122 \_\mathrm{B} 11$ & 12 & 4 & $2 / 1$ \\
\hline & & & $\mathrm{T}_{1}-122 \_\mathrm{C} 6$ & 12 & 1 & $0 / 1$ \\
\hline & & & $\mathrm{T}_{1}-122 \_\mathrm{F} 12$ & 12 & 4 & $0 / 3$ \\
\hline & & & $\mathrm{T}_{1}-122 \_\mathrm{H} 2$ & 12 & 0 & - \\
\hline & & & $\mathrm{T}_{1}-122 \_\mathrm{H} 4$ & 12 & 3 & $0 / 0$ \\
\hline & & & $\mathrm{T}_{1}-122 \_\mathrm{H} 9$ & 12 & 0 & - \\
\hline \multirow[t]{3}{*}{ pPM19-3 } & \multirow[t]{3}{*}{$T_{0}-211$} & \multirow[t]{3}{*}{ Heterozygous } & $\mathrm{T}_{1}-211 \_\mathrm{B} 11$ & 12 & 3 & $0 / 0$ \\
\hline & & & $\mathrm{T}_{1}-211 \_\mathrm{D} 10$ & 12 & 0 & - \\
\hline & & & $\mathrm{T}_{1}-211 \_\mathrm{G} 4$ & 7 & 0 & - \\
\hline
\end{tabular}

${ }^{a}$ Hyphens (-) indicate that all plants had presence of the T-DNA construct, and thus were not tested

of Cas9-induced mutations in barley in the absence of the T-DNA.

The ability to develop transgene-free and stable germline mutations is of considerable interest in crop species given the current regulatory framework for deployment of transgenic crops in the field. Although regulation of edited crops is still being debated [20], crops free of transgenes may not be subject to existing regulations on genetic modification. Here, we demonstrate that in several instances there was stable germline-transmitted inheritance of Cas9-induced mutations in barley from the $T_{1}$ to the $T_{2}$ generation in the absence of the T-DNA construct. This supports previous studies in plants (Arabidopsis, tomato, tobacco and rice) that have documented transgene-free inheritance of Cas9-induced mutations in the $T_{1}$ and $T_{2}$ generations. No description of germline inheritance has been previously reported for Triticeae [12]. We also identified a single plant with an off-target mutation in the $\mathrm{T}_{2}$ generation in the absence of the T-DNA construct. This plant had mutations in both HvPM19-1 and HvPM19-3, suggesting that tandemly duplicated genes can be knocked-out with a single sgRNA, although we have yet to establish if these mutations are in cis or on homologous chromosomes. Previous work in rice had identified off-target mutations only in the $T_{1}$ generation and in the presence of the sgRNA/Cas9 construct [21].

\section{RNA-guided Cas9 induced genome editing in Brassica} oleracea

RNA-guided Cas9-induced genome editing was performed in B. oleracea DH1012 [22] by targeting BolC.GA4.a 
a HvPm19-1 Wild type Allele:

$\mathrm{T}_{1}$-181-E1 Mutant Allele:

$\mathrm{T}_{2}$-181-E1-p3, p5, p6, p9 and p10:

b

$\mathrm{T}_{1}-181-\mathrm{A} 11$ WT Allele:

$\mathrm{T}_{1}-181-\mathrm{A} 11$ Mutant Allele 1:

$\mathrm{T}_{1}-181-\mathrm{A} 11$ Mutant Allele 2:

$\mathrm{T}_{2}$-181-A11-p11:

$\mathrm{T}_{1}$-181-D2 WT Allele:

$\mathrm{T}_{1}-181-\mathrm{D} 2$ Mutant Allele:

$\mathrm{T}_{2}$-181-D2-p11 and p12:

$\mathrm{T}_{1}$-181-D11 WT Allele:

$\mathrm{T}_{1}-181-\mathrm{D} 11$ Mutant Allele:

$\mathrm{T}_{2}-181-\mathrm{D} 11-\mathrm{p} 7$ :

$\mathrm{T}_{1}-181-\mathrm{H} 2$ WT Allele:

$\mathrm{T}_{1}-181-\mathrm{H} 2$ Mutant Allele:

$\mathrm{T}_{2}-181-\mathrm{H} 2-\mathrm{p} 9$ :

$\mathrm{T}_{1}-122-\mathrm{B} 11$ WT Allele:

$\mathrm{T}_{1}-122-\mathrm{B} 11$ Mutant Allele:

$\mathrm{T}_{2}-122-\mathrm{B} 11-\mathrm{p} 8$ and $\mathrm{p} 12$ :

C

BolC.GA4.a Wild type Allele:

$\mathrm{T}_{1}$ L2F1_E_B6:

$\mathrm{T}_{2}-\mathrm{L} 2 \mathrm{~F} 1-\mathrm{E}$ B6_p6 and $\mathrm{p} 7$ :

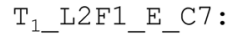

$\mathrm{T}_{2}-\mathrm{L} 2 \mathrm{~F} 1-\mathrm{E} \_\mathrm{C} 7 \mathrm{p} 1, \mathrm{p} 4, \mathrm{p} 9$ and $\mathrm{p} 10$ :

T1_L2F1_E_D8:

$\mathrm{T}_{2}-\mathrm{L} 2 \mathrm{~F} 1-\mathrm{E}-\mathrm{D} 8 \_\mathrm{p} 2, \mathrm{p} 7$ and $\mathrm{p} 9$ :
CTGTACGTGCTTGCTCTCCACTCTGGGCTCTTCGGAAACCAGTTTGGTAA

CTGTACGTGCTTGCTCTCCACTCTGGGC-CTTCGGAAACCAGTTTGGTAA

CTGTACGTGCTTGCTCTCCACTCTGGGC-CTTCGGAAACCAGTTTGGTAA

CTGTACGTGCTTGCTCTCCACTCTGGGCT-CTTCGGAAACCAGTTTGGTAA CTGTACGTGCTTGCTCTCCACTCTGGGCTTCTTCGGAAACCAGTTTGGTAA CTGTACGTGCTTGCTCTCCACTCTGGGC---TTCGGAAACCAGTTTGGTAA CTGTACGTGCTTGCTCTCCACTCTGGGC---TTCGGAAACCAGTTTGGTAA

CTGTACGTGCTTGCTCTCCACTCTGGGCTCTTCGGAAACCAGTTTGGTAA CTGTACGTGCTTGCTCTCCACTCTGGGC-CTTCGGAAACCAGTTTGGTAA CTGTACGTGCTTGCTCTCCACTCTGGGC-CTTCGGAAACCAGTTTGGTAA

CTGTACGTGCTTGCTCTCCACTCTGGGCT-CTTCGGAAACCAGTTTGGTAA CTGTACGTGCTTGCTCTCCACTCTGGGCTTCTTCGGAAACCAGTTTGGTAA CTGTACGTGCTTGCTCTCCACTCTGGGCTTCTTCGGAAACCAGTTTGGTAA

CTGTACGTGCTTGCTCTCCACTCTGGGCT-CTTCGGAAACCAGTTTGGTAA x8 CTGTACGTGCTTGCTCTCCACTCTGGGCTACTTCGGAAACCAGTTTGGTAA $\quad$ x CTGTACGTGCTTGCTCTCCACTCTGGGCTACTTCGGAAACCAGTTTGGTAA CTGTACGTGCTTGCTCTCCACTCTGGGCT-CTTCGGAAACCAGTTTGGTAA $\quad$ x10 CTGTACGTGCTTGCTCTCCACTCTGGGCTTCTTCGGAAACCAGTTTGGTAA $\quad$ 5 CTGTACGTGCTTGCTCTCCACTCTGGGCTTCTTCGGAAACCAGTTTGGTAA
GTGGTCCGAAGGTTTTACCATCACCGGCTCCCCTCTCAACGACTTCCGTAA GTGGTCCGAAGGTTTTACCATCA------CCCCTCTCAACGACTTCCGTAA GTGGTCCGAAGGTTTTACCATCA------CCCCTCTCAACGACTTCCGTAA
GTGGTCCGAAGGTTTTACCATCA------CCCCTCTCAACGACTTCCGTAA GTGGTCCGAAGGTTTTACCATCA------CCCCTCTCAACGACTTCCGTAA
GTGGTCCGAAGGTTTTACCATCA------CCCCTCTCAACGACTTCCGTAA GTGGTCCGAAGGTTTTACCATCA------CCCCTCTCAACGACTTCCGTAA

Fig. 4 Germline transmission of Cas9 induced mutations from $T_{1}$ to $T_{2}$ plants in barley and B. oleracea in the absence of the T-DNA construct. a Sequence alignment of $T_{1}-181 \_E 1$ and five homozygous $T_{2}$ progeny with homozygous 1-bp deletion in HvPM19_1. b Sequence alignment from representative clones of $T_{1}$ heterozygote mutants and direct Sanger sequencing of their $T_{2}$ progeny with homozygous mutations in the absence of the T-DNA. The numbers of clones supporting $T_{1}$ mutant alleles are indicated on the right. c Sequence alignments of BolC.GA4.a Target 2 in homozygous $T_{1}$ and T-DNA free $T_{2}$ plants. Across panels the target sequences for sgRNAHvPM19-1 and sgRNABolC.GA4.a (grey) and PAM (red) are highlighted and Cas9 induced insertions and deletions are indicated by red font or red hyphens, respectively. Names of homozygous $T_{2}$ plants that lack the presence of the T-DNA construct are indicated in blue; individual homozygous plants with the same allele are shown on the same row and are labelled with a 'p' prefix

(Bol038154) located on chromosome 5. This gene is an orthologue of Arabidopsis GA4 which encodes AtGA3OX1, the last enzyme in the biosynthesis of bioactive gibberellins. In Arabidopsis, ga4 loss-of-function mutants show a semidwarf phenotype [23] and this gene is required for efficient seed dispersal as it promotes specification of the dehiscence zone in siliques [13]. BolC.GA4. $a$ has a paralog on chromosome 8, designated BolC.GA4.b (Bol031570), which shares 90 \% DNA sequence identity. To generate Cas9 induced mutations in BolC.GA4.a, we designed a binary construct containing two sgRNAs (sgRNA1BolC.GA4.a and sgRNA2BolC.GA4.a) that target separate regions (Target 1 and Target 2, respectively) in the first exon of BolC.GA4.a (Figs. 1b and $2 b$ ).

Eighty independent transgenic lines were generated by Agrobacterium-mediated transformation, and 20 of these $\mathrm{T}_{0}$ plantlets were screened by the restriction digest/PCR assay to detect mutations in the target sequences. We 
identified in-dels at the target sites in BolC.GA4.a in two out of $20 \mathrm{~T}_{0}$ lines (L2F1_8.2 and L2E1_17.1). Mutations in L2E1_17.1 were confirmed by TA cloning and Sanger sequencing of the PCR products (Fig. 5a). Line L2F1_8.2 showed a 282-bp deletion that corresponds to re-joining of the DNA at exactly $3 \mathrm{bp}$ from the PAM in both target regions. As in barley, the detection of the mutations required an enrichment of the target by restriction digest prior to PCR.

We also hypothesised that plants with homozygous mutations in BolC.GA4.a would show a dwarf phenotype similar to that observed in Arabidopsis ga4 mutants. Therefore, we performed a phenotypic screen of the $80 \mathrm{~T}_{0}$ B. oleracea plants. All $80 \mathrm{~T}_{0}$ lines were grown to maturity, and at flowering two lines not previously characterised by the restriction digest/PCR assay were observed to be dwarf in stature (L2F1_A and L2F1_E; Fig. 6a). The BolC.GA4.a sequences from both dwarf plants were found to contain a series of mutant alleles in Target 1 and Target 2, in two independent leaf samples from each plant (Fig. 5b, Additional file 2). In addition, the mutation was restricted to BolC.GA4.a, as we were unable to detect any mutation in BolC.GA4.b. The identification of $\mathrm{T}_{0}$ plants with a visible knockout phenotype has also been reported in rice, tomato, and Arabidopsis $[8,10,24]$.

The $80 \mathrm{~T}_{0}$ B. oleracea plants described above originated from the same transformation experiment, but differed in their culture period. A first batch of $41 \mathrm{~T}_{0}$ shoots was isolated four weeks after Agrobacterium inoculation, whereas a second batch of $39 \mathrm{~T}_{0}$ shoots was isolated 7 weeks after inoculation. Both dwarf lines were derived from the 7-week batch, supporting a recent report in rice [25] that obtained an increased proportion and variety of mutated cells by extending the culture period of rice calli by 4 weeks. Across different target genes, Mikami et al. [25] found a 3.7-fold increase in mutation frequencies between rice calli cultured for 1 month compared to 2 months. They hypothesize that this is due to a greater chance of inducing novel mutations in non-mutated cells [25]. Our results are consistent with this hypothesis which also implies that shorter selection periods during culture of calli could reduce the number of off-target mutations.

\section{Cas9-induced mutations are stably transmitted to $T_{2}$} B. oleracea plants independently of the T-DNA construct

To examine the mutation frequency of the target locus BolC.GA4.a, the $\mathrm{T}_{1}$ progenies of lines L2F1_8.2 and L2E1_17.1 were screened for Cas9-induced mutations in Target 1 and 2 by PCR amplification of BolC.GA4.a followed by direct sequencing. Using the sequencing chromatograms it was possible to identify homozygous and heterozygous mutations. We detected mutations in the $\mathrm{T}_{1}$ progenies of L2F1_8.2, but not in L2E1_17.1. Heterozygous in-dels were observed in 68 of 90 L2F1_8.2 $\mathrm{T}_{1}$ progenies; however, no homozygous mutations were identified. Of these $68 \mathrm{~T}_{1}$ plants, 35 had mutations in Target 1, whereas Target 2 was mutated in 67 lines, suggesting a higher efficiency of the Target 2

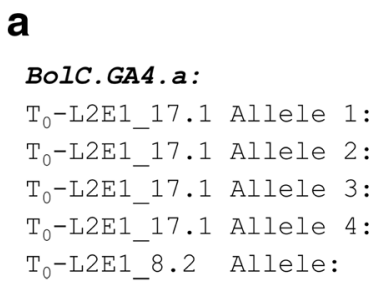

b

\section{BoIC.GA4.a:}

$\mathrm{T}_{0}-\mathrm{L} 2 \mathrm{~F} 1$ A Allele 1:

$\mathrm{T}_{0}-\mathrm{L} 2 \mathrm{~F} 1$ A Allele 2:

$\mathrm{T}_{0}-\mathrm{L} 2 \mathrm{~F} 1$ E Allele 2:

$\mathrm{T}_{0}-\mathrm{L} 2 \mathrm{~F} 1$ E Allele 3:

$\mathrm{T}_{0}$-L2F1_E Allele 4:
$\mathrm{T}_{0}-\mathrm{L} 2 \mathrm{~F} 1$ E Allele 1:

\section{Target 1}

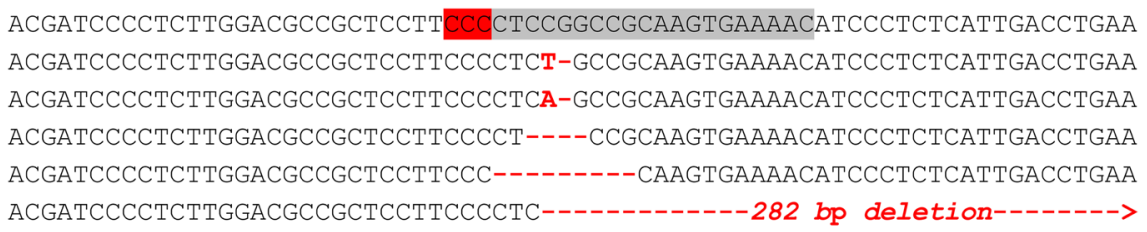

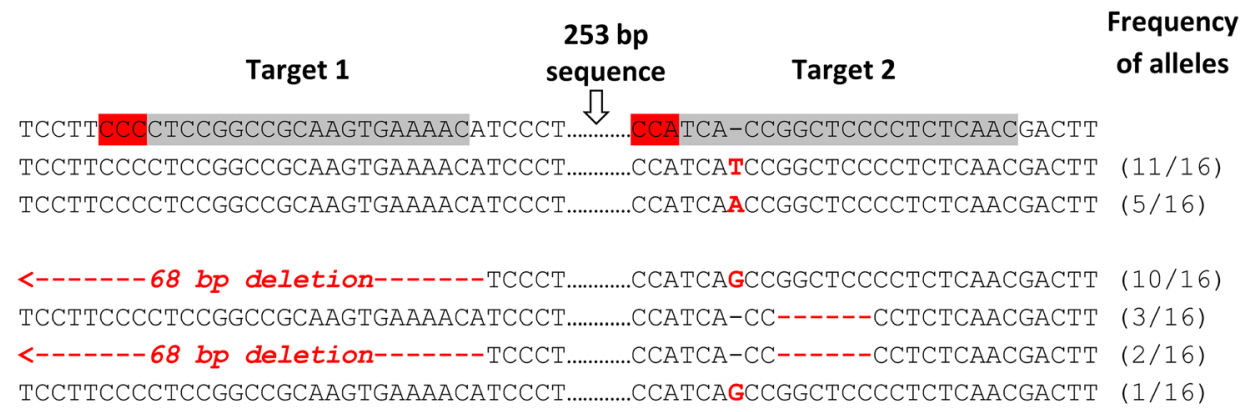

Fig. 5 Mutant alleles detected in $T_{0}$ B. oleracea. Alignment of wild-type and mutant sequences surrounding the target sequences (grey highlight) and PAM (red highlight) in mutants identified by restriction digest/PCR screen (a) and by phenotypic screen (b). Insertions and deletions are indicated by red font or red hyphens, respectively. For large deletions, red arrows indicate the direction of the deletions. For each line in panel $b$ (L2F1_A and L2F1_E), 16 clones were examined and the frequencies of each mutant allele (represented as clones with mutant allele/total number of clones examined) are indicated at the right side of the panel 

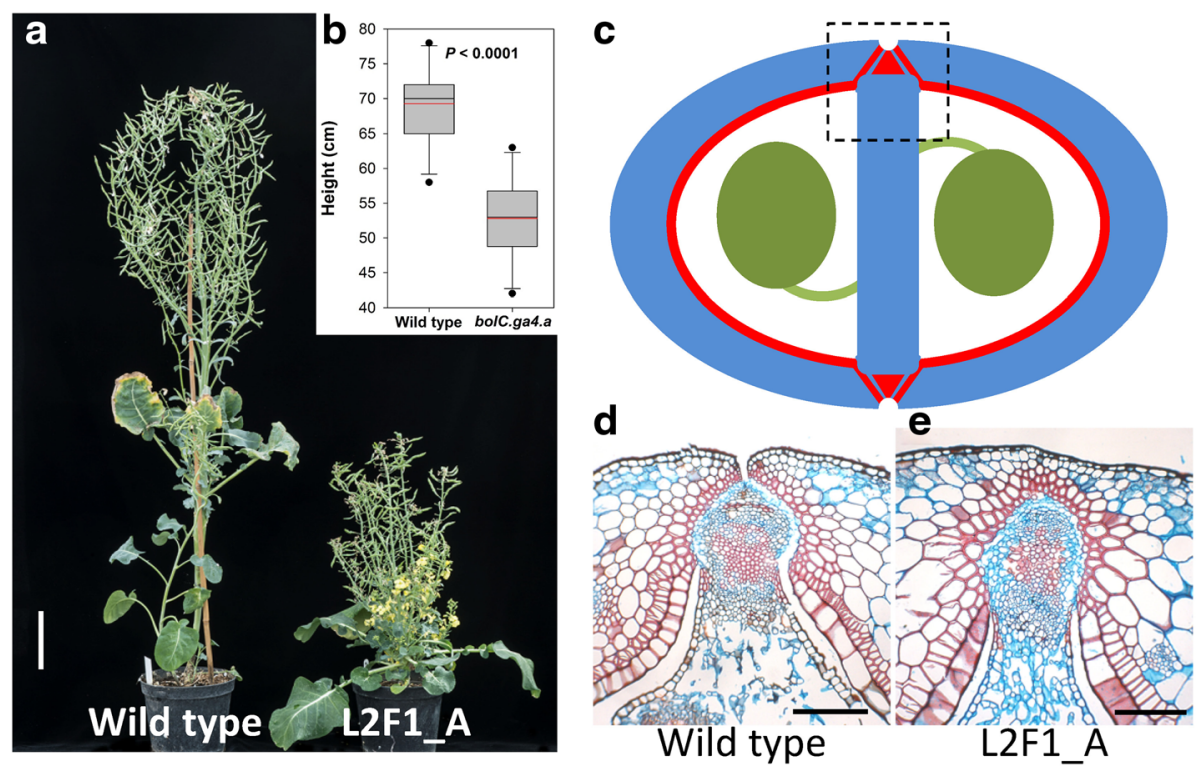

Fig. 6 Mutations in BolC.GA4.a result in dwarf stature and affect the pod valve margin. a Wild-type B. oleracea DH1012 (left) and L2F1_A with a mutation in BolC.GA4.a showing a severe dwarf phenotype. Scale bar $10 \mathrm{~cm}$. b Height of homozygous $\mathrm{T}_{1}$ plants with wild type $(n=11)$ or bo/C.ga4.a mutant $(n=16)$ alleles. c Schematic cross section of B. oleracea pod with replum/valve margin region indicated by dashed square. Lignified tissue is indicated in red, unlignified cells are indicated in blue, and developing seeds are in green. $\mathbf{d}$, e Cross-section of replum valve margin region of B. oleracea wild-type pod (d) and L2F1_A mutant pod (e); scale bars $200 \mu \mathrm{m}$

sgRNA (Fig. 7b). None of the $90 \mathrm{~T}_{1}$ progenies inherited the complete 282-bp deletion between the two BolC.GA4.a target regions that was observed in the $\mathrm{T}_{0}$ generation.

The sgRNA targets were also sequenced in the $\mathrm{T}_{1}$ progenies of lines L2F1_A and L2F1_E that showed a dwarf phenotype. $\mathrm{T}_{1}$ plants from each of L2F1_A and L2F1_E were screened and found to carry a range of either homozygous or heterozygous mutations across the target regions in
BolC.GA4.a (Additional file 2). Of the 39 plants screened, 20 had either homozygous mutations or a combination of two mutant alleles previously identified in the $\mathrm{T}_{0}$ plants; all of these plants displayed the dwarf phenotype at maturity (Fig. 6b). In the remaining 19 heterozygous lines we also identified the same mutations as in the $\mathrm{T}_{0}$ plants, including the large 68-bp deletion across Target 1 (Fig. 5b; Additional file 2). These results are consistent with stable transmission of Cas9-induced mutant alleles in B. oleracea.

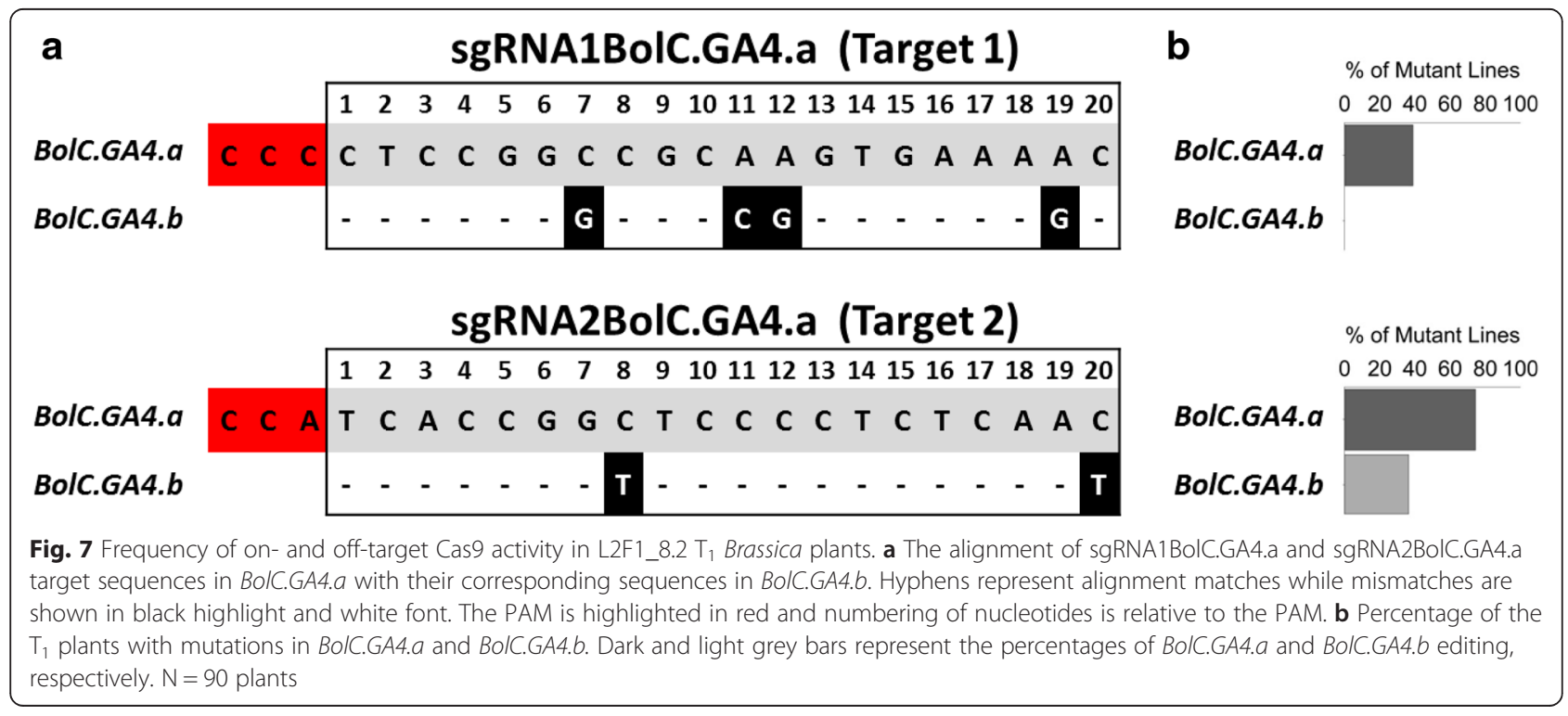


To determine germline inheritance, we screened for the presence of the T-DNA construct in 12 individual $\mathrm{T}_{2}$ plants derived from eight homozygous mutant $T_{1}$ lines (96 plants in total). Nine $\mathrm{T}_{2}$ plants which lacked the T-DNA construct were recovered (Fig. 4c). These plants all carried the same 6-bp deletion in Target 2, and wild-type allele in Target 1 , as in the parental $T_{1}$ plants (L2F1_E_B6, L2F1_E_C7, and L2F1_E_D8). The fact that the mutations in $\mathrm{T}_{1}$ plants were stably transmitted to the $\mathrm{T}_{2}$ generation in the absence of the T-DNA construct supports the germline inheritance of the Cas9induced mutations in B. oleracea.

\section{Off-target activity of RNA-guided Cas9 in $\mathrm{T}_{1}$ transgenic B. oleracea plants}

Sequencing of BolC.GA4.b in the $\mathrm{T}_{1}$ progenies of $\mathrm{T}_{0^{-}}$ L2F1_8.2 revealed off-target activity in 32 out of 88 plants (36.4 \%; Fig. 7b). This was restricted to Target 2 where the sgRNA contained two mismatches with BolC.GA4.b (Fig. 7a). No mutations were observed across Target 1 where the sgRNA contained four mismatches in the target region compared to BolC.GA4.b. In $\mathrm{T}_{0}$ lines with the dwarf phenotype $\left(\mathrm{T}_{0}\right.$ lines L2F1_A and L2F1_E), we detected no off-target activity in BolC.GA4.b, indicating that the dwarf phenotype was due to mutations in BolC.GA4.a only.

In this study, we show that a single sgRNA (sgRNA2BolC.GA4.a) can simultaneously target two copies of GA4 despite the presence of a mismatch between the sgRNA and the BolC.GA4.b off-target sequence 8 bp from the PAM (Fig. 7a). This observation mirrors our results in barley, in which off-target activity was detected in $H v P M 19-3$ due to the sgRNA in pPM19-1, designed to target $H v P M 19-1$ and which has a mismatch 9 bp from the PAM (Fig. 3). This off-target activity was detected only in the progeny of the $B$. oleracea and barley lines with high on-target mutation frequencies. Given these results and the idea that on-target mutations may precede off-target mutations [26], it is tempting to speculate that higher on-target Cas9 activity positively correlates with higher off-target mutation frequencies.

These results differ from reports in wheat, where a single mismatch $3 \mathrm{bp}$ from the PAM between $M L O$ homoeologues limited off-target activity, although ontarget mutation frequencies were relatively low (5.6\%; [12]). Previous studies found that a single mismatch within the $12 \mathrm{bp}$ adjacent to the PAM could confer specificity in humans and other systems [3, 27]. However, others $[28,29]$ have shown that up to two mismatches, as well as small insertions and deletions, are tolerated within this sequence. Taken together, these results suggest that additional work is needed to decipher the key design rules and experimental parameters relating to onand off-target mutations using the Cas9 system.
The presence of off-target activity can be considered a negative feature of the Cas9 system when specificity is sought. Several approaches have been suggested for the reduction of off-target activity. These include using truncated sgRNAs [30], a pair of Cas9 nickase mutants directed to opposing strands that require a pair of correctly positioned $20 \mathrm{bp}$ DNA targets to produce a DSB $[31,32]$, and also the fusion of catalytically dead Cas9 (dCas9) to homodomains of a FokI nuclease dimer that will also only produce a DSB when both targets are in correct proximity [33, 34]. However, off-target activity can also be beneficial for targeting gene families [26] or closely related sequences. Our results suggest that a single sgRNA can simultaneously target multiple gene copies facilitating gene functional analysis by overcoming possible redundancy between the closely related sequences [35]. Importantly, we identified an individual transgene-free barley plant that had concurrent heterozygous mutations in the target (HvPM19-1) and off-target (HvPM19-3) genes. Many crop species are polyploid (for example, wheat, potato), have undergone recent wholegenome duplication events (for example, Brassica, maize; [36]), or have a high number of tandemly duplicated genes [37], such as the HvPM19 locus investigated in this study. Therefore, the potential to generate progeny with mutations limited to on-target sites, as well as progeny with both on- and off-target mutations, makes the RNA-guided Cas9 system especially relevant for functional analyses in crops.

\section{Mutations in BolC.GA4.a affect the pod valve margin}

Tissue patterning in the fruits of Arabidopsis and members of the Brassica genus is highly similar reflecting their close evolutionary relationship [38]. Seed dispersal in these species depends on formation of valve margin cells along the valve and replum borders that mediate fruit opening [39]. Since valve margins from Arabidopsis ga4 mutants fail to mediate efficient seed dispersal [13], we tested if the $B$. oleracea Cas9 lines presented here suffered from similar defects. Cross-sections stained with a combination of Safranin $\mathrm{O}$ and Alcian Blue revealed that in comparison to wild-type fruits, fruits from L2F1_A failed to pattern the valve margin region properly, such that valve cells replaced the valve margin cells in this line (Fig. 6c-e). As a result, these fruits would disperse their seeds less efficiently than wild type. Although less severe, this phenotype resembled the phenotype observed when another regulator of valve margin formation, BolC.IND.a, was downregulated by RNAi [38]. These data therefore demonstrate that the BolC.GA4.a function is conserved between B. oleracea and Arabidopsis and likely regulated in a similar fashion. They also demonstrate the potential for the use of RNA-guided Cas9 to target important traits in Brassica crops based on knowledge of gene function from model plants. 


\section{Conclusions}

In this study, we demonstrate the use of RNA-guided Cas9 to induce targeted mutations in two crop species, B. oleracea and barley, and report stable transmission of the mutations across generations. We show that knockout phenotypes can be recovered as early as the primary $\mathrm{T}_{0}$ generation, exemplifying the use of this technology for rapid analyses of gene function. We produced transgene-free barley and B. oleracea plants with stablyinherited mutations in the target gene, supporting the potential for downstream biotechnological applications. Both species showed off-target activity, despite the presence of at least one mismatch between the sgRNA and the paralogous gene. This led to the identification of a single barley plant with concurrent mutations in the target and off-target gene in the absence of the T-DNA construct. Our results suggest that experimental parameters relating to on- and off-target mutations need to be carefully considered and monitored, and that a single sgRNA has the potential to generate progeny with simultaneous knock-out mutations in paralogous genes. Given that crop genomes commonly contain multiple closely related sequences, the features described herein make RNA-guided Cas9 especially relevant for functional analyses in these species.

\section{Materials and methods}

\section{Target locus selection and sgRNA design}

Gene sequences for B. oleracea BolC.GA4.a (Bol038154) and barley HvPm19 (AF218627.1; [15]) were obtained from The Brassica Database [40] and the International Barley Sequencing Consortium [41] databases. For barley, sequence of the BAC clone HVVMRXALLmA0022M08 from the cultivar 'Morex' was kindly provided pre-publication by Dr Nils Stein (IPK). This BAC was annotated and four copies of $H \nu P m 19$ were identified (HvPM19-1 to HvPM19-4). Target sequences that conformed to $\mathrm{G}(\mathrm{N})_{20} \mathrm{GG}$ were identified on sense and antisense strands in the coding sequence for BolC.GA4.a and for HvPM19-1 and HvPM19-3 and potential off-target sequences were detected via BLAST searches $[40,41]$. Potential targets were also evaluated for the presence of non-CpG sensitive restriction site sequences predicted to be disrupted by Cas9 induced in-dels, which also had to be unique within a PCR amplicon. Final target sequences were chosen to be as specific as possible to the intended target sequence (that is, keeping the number of mismatches to off-target sequences high), close to the start codon, and to include an appropriate restriction site (Fig. 1). These targets were checked by PCR and Sanger sequencing (Additional file 3 ) in the varieties to be transformed (spring barley cultivar 'Golden Promise' and Brassica oleracea DH1012) to ensure that no polymorphisms existed between the sgRNA and the target $G(N){ }_{20} G G$ sequences. Single sgRNAs were used for barley HvPM19-1 and HvPM19-3, whereas two independent sgRNAs were targeted to the first exon of Brassica BolC.GA4.a. Barley 'Golden Promise' sequences for the three HvPM19 genes were deposited in GenBank (accession numbers KT336449-KT336451).

\section{Construct assembly}

The binary plasmid vector constructs were assembled using Golden Gate Modular Cloning (MoClo) [42]. We used Level 0 parts from the Golden Gate MoClo Plant Parts Kit (Addgene kit \# 1000000047) and plasmids from Golden Gate MoClo Plant Toolkit (Addgene kit \# 1000000044) described in Engler et al. [43]. Level 1 transcriptional units were assembled from Level 0 parts and these were subsequently assembled to make the plasmids vectors shown in Fig. 2. A detailed protocol for the assembly of binary vectors with multiple sgRNAs using the Golden Gate MoClo ToolKit and the identity of all plasmids used are given in Additional file 4. Annotated sequences of the plasmids made in this study are provided in Additional file 5 and are available at the non-profit plasmid depository AddGene (https://www.addgene.org/browse/article/14759/).

\section{Plant transformation and screening of transgenic material} Barley ( $c v$. 'Golden Promise') was transformed by Agrobacterium tumefaciens-mediated transformation of immature embryos as described by Harwood [44]. Brassica oleracea (DH1012) was transformed by Agrobacterium tumefaciens infection of 4-day-old cotyledonary petioles according to Hundleby and Irwin [45].

Primary transgenic $\mathrm{T}_{0}$ materials were screened using a modified restriction enzyme site loss method [46]. Briefly, for single sgRNA targets, genomic DNA was digested prior to PCR with a CpG-insensitive enzyme to remove wild-type template and thus favour the PCR amplification of mutant DNA where the restriction site had been lost. For Brassica, where a pair of sgRNAs was used, an additional screen was implemented; a CpGinsensitive restriction enzyme (AflII) was used prior to PCR to enrich for mutant DNA where the fragment between the two guides had been removed. PCR amplification across the region thus led to shorter PCR products than expected from a wild-type individual.

DNA was extracted according to Edwards et al. [47] from rooted shoots of less than $10 \mathrm{~cm}$ in height and quantified using a Nanodrop 8000 (Thermo Scientific). Genomic DNA (100 ng) was digested overnight with 20 units of the appropriate restriction enzyme shown in Fig. 1 (SapI, HaeIII, HphI, AflII (NEB); MaeIII (Roche)) and then purified using a Qiagen QIAquick Gel Extraction Kit (final elution with $25 \mathrm{uL}$ of water). Purified digested DNA $(5 \mu \mathrm{L})$ was used as PCR template to amplify across the target regions using gene-specific primers (Additional 
file 3). PCR products were confirmed by agarose gel electrophoresis, purified using the QIAquick Gel Extraction Kit, and Sanger sequenced (Eurofins MWG) to confirm the presence of in-dels. Where the amplicon was too short for direct sequencing, the PCR product was first cloned using the pGEMT-Easy kit (Promega) according to the manufacturer's instructions and then sequenced with M13 universal primers.

The detection of mutations in $\mathrm{T}_{1}$ and $\mathrm{T}_{2}$ transgenic lines was performed though Sanger sequencing of PCR amplicons produced using genomic DNA template that was not digested prior to PCR (Additional file 3). Sequences were compared to wild type to detect the presence of homozygous in-dels. Chromatograms were also examined to identify overlapping traces in the region surrounding the PAM, indicative of the presence of mutations. The presence of the T-DNA construct was assessed in progenies of active lines by PCR amplification of the nptII CDS in Brassica and hptII CDS in barley (Additional file 3).

\section{Phenotyping of $B$. oleracea transgenic lines}

The 80 primary $\mathrm{T}_{0}$ transgenic lines and corresponding controls were grown in a controlled environment room with $16 \mathrm{~h}$ light (high-pressure sodium lamps with an average bench reading of $200 \mu \mathrm{mol} / \mathrm{m}^{2} / \mathrm{s}$ ) at $12{ }^{\circ} \mathrm{C}$ and $8 \mathrm{~h}$ dark at $12{ }^{\circ} \mathrm{C}$ and constant $65-75 \%$ humidity. Plant height was measured at final maturity. Seed pods at developmental stage 17 [48] were collected from dwarf line L2F1_A and the wild-type DH1012 control. Pods were fixed for $16 \mathrm{~h}$ in FAA solution $(3.7 \%$ formaldehyde, $5 \%$ acetic acid, $50 \%$ ethanol) and subsequently dehydrated through an ethanol series consisting of $50 \%, 60 \%$, $70 \%, 80 \%, 90 \%, 95 \%$, and $100 \%$ ethanol for 30 min each at room temperature. The tissues were cleared with Histoclear (National Diagnostics,) and embedded in paraffin wax. Transverse sections $8 \mu \mathrm{m}$ thick were cut using an RM 2055 rotary microtome (Leica) and mounted on Polysine $^{\mathrm{Tm}}$ slides (VWR International).The wax was removed using Histoclear and sections stained using an Alcian Blue/Safranin-O solution (0.05 \% Alcian Blue and $0.01 \%$ Safranin-O in $0.1 \mathrm{M}$ acetate buffer (pH5.0)) as described by Østergaard et al. [49]. Sections were examined by light microscopy using a Zeiss Axioplan microscope and images captured using a Leica DFC 320 camera with Leica Application Suite software.

\section{T-DNA copy number and presence/absence determination in transgenic barley}

Quantitative real-time PCR was used to determine copy number $\left(\mathrm{T}_{0}\right)$ and presence/absence $\left(\mathrm{T}_{2}\right)$ of the T-DNA in transgenic barley and $B$. oleracea lines. The reaction compared the Cq values of an HptII (Fig. 2a) amplicon to a single-copy barley gene CO2 (Constans-like, AF490469) amplicon and the Cq values of an NptII amplicon to a single-copy B. oleracea gene GL2-like (Bol021421) within a single multiplexed assay (Additional file 3). The reactions used Thermo ABGene Absolute QPCR Rox Mix (Cat number AB1139) with the probes and primers at a final concentration of $200 \mathrm{nM}$ (HptII and NptII) and 100nM (CO2 and GL2). The assay contained $5 \mu \mathrm{L}$ DNA solution, and was optimised for final DNA concentrations of 1 to $10 \mathrm{ng} / \mu \mathrm{L}$ ( 5 to $50 \mathrm{ng}$ DNA in the assay). PCRs were carried out in a Bio-Rad CFX96 machine (C1000 Touch). The detectors used were FAM-TAMRA and VIC-TAMRA for barley and HEX-BHQ1 and FAM-BHQ1 for B. oleracea. The PCR cycling conditions were $95{ }^{\circ} \mathrm{C}$ for $15 \mathrm{~min}$ (enzyme activation), 40 cycles of $95^{\circ} \mathrm{C}$ for $15 \mathrm{~s}$, and $60{ }^{\circ} \mathrm{C}$ for $60 \mathrm{~s}$. Each sample was analysed twice and for presence/absence determinations, two independent DNA extractions of the $\mathrm{T}_{2}$ transgenic plants were used. Cq values were determined using the accompanying CFX96 software (version 3.1), with $\mathrm{Cq}$ determination set to regression mode. Values obtained were used to calculate T-DNA copy number according to published methods [50].

\section{Additional files}

Additional file 1: Chromatogram traces of $\mathrm{T}_{0}-181$ and $\mathrm{T}_{0}-191$
plants. (JPG $439 \mathrm{~kb}$ )
Additional file 2: Analysis of BolC.GA4.a sequences in $\mathrm{L} 2 \mathrm{~F} 1 \_\mathrm{A}$ and
$\mathrm{L} 2 \mathrm{~F} 1 \_\mathrm{E} \mathrm{T}_{0}$ and $\mathrm{T}_{1}$ plants. (DOCX $25 \mathrm{~kb}$ )
Additional file 3: Primers and probes used in this study. (XLSX $12 \mathrm{~kb}$ )
Additional file 4: Detailed methods for assembly of binary vectors
with multiple sgRNAs using the Golden Gate MoCloToolKit. (DOCX $28 \mathrm{~kb}$ )
Additional file 5: Genbank files (.gb) of the 14 plasmids submitted
to AddGene. (ZIP $41 \mathrm{~kb}$ )

\section{Competing interests}

The authors declare that they have no competing interests.

\section{Authors' contributions}

$\mathrm{TL}, \mathrm{OS}$ and NP designed and generated the constructs used in this study; $\mathrm{TL}$ generated the transgenic lines; TL and OS performed the molecular characterisation of the transgenic lines; NS performed the phenotypic characterisation of $B$. oleracea lines; $C L$ provided pre-publication access to barley BAC sequence; $\mathrm{WH}$ and $\mathrm{CU}$ designed the experiments. TL, OS, NS, LO, $\mathrm{NP}, \mathrm{CU}$ and $\mathrm{WH}$ contributed to the writing of the manuscript and all authors reviewed the final version. All authors read and approved the final manuscript.

\section{Acknowledgments}

The authors would like to thank Dr Nils Stein (IPK), Xiao-Qi Zhang (Murdoch University), Guoping Zhang (Zhejiang University) and Mr Simon Lee (BGI-Shenzhen) for providing pre-publication access to barley Morex BAC sequences.

Funding

This work was supported by the Institute Strategic Programme grant BB/ J004553/1 from the UK Biotechnology and Biological Sciences Research Council (BBSRC), the BBSRC and Engineering and Physics Research Council (EPSRC) Synthetic Biology Research Centre award (BB/L014130/1), by the John Innes Centre Innovation fund, the John Innes Foundation and the Gatsby Charitable Foundation. 


\section{Author details}

${ }^{1}$ John Innes Centre, Norwich Research Park, Colney NR4 7UH, UK. ${ }^{2}$ Western Barley Genetics Alliance, Murdoch University, Murdoch WA6150, Australia.

${ }^{3}$ The Sainsbury Laboratory, Norwich Research Park, Colney NR4 7UH, UK.

\section{Received: 30 July 2015 Accepted: 5 November 2015} Published online: 30 November 2015

\section{References}

1. Voytas DF, Gao C. Precision genome engineering and agriculture: opportunities and regulatory challenges. PLoS Biol. 2014;12:e1001877.

2. Hsu Patrick D, Lander Eric S, Zhang F. Development and applications of CRISPR-Cas9 for genome engineering. Cell. 2014;157:1262-78.

3. Cong L, Ran FA, Cox D, Lin S, Barretto R, Habib N, et al. Multiplex genome engineering using CRISPR/Cas systems. Science. 2013;339:819-23.

4. Mali P, Yang L, Esvelt KM, Aach J, Guell M, DiCarlo JE, et al. RNA-guided human genome engineering via Cas9. Science. 2013;339:823-6.

5. Belhaj K, Chaparro-Garcia A, Kamoun S, Patron NJ, Nekrasov V. Editing plan genomes with CRISPR/Cas9. Curr Opin Biotechnol. 2015;32:76-84.

6. Li J-F, Norville JE, Aach J, McCormack M, Zhang D, Bush J, et al. Multiplex and homologous recombination-mediated genome editing in Arabidopsis and Nicotiana benthamiana using guide RNA and Cas9. Nat Biotech. 2013;31:688-91.

7. Nekrasov V, Staskawicz B, Weigel D, Jones JDG, Kamoun S. Targeted mutagenesis in the model plant Nicotiana benthamiana using Cas 9 RNA-guided endonuclease. Nat Biotech. 2013;31:691-3.

8. Shan Q, Wang Y, Li J, Zhang Y, Chen K, Liang Z, et al. Targeted genome modification of crop plants using a CRISPR-Cas system. Nat Biotech. 2013:31:686-8

9. Feng Z, Mao Y, Xu N, Zhang B, Wei P, Yang D-L, et al. Multigeneration analysis reveals the inheritance, specificity, and patterns of CRISPR/Cas-induced gene modifications in Arabidopsis. Proc Natl Acad Sci. 2014;111:4632-7.

10. Zhang H, Zhang J, Wei P, Zhang B, Gou F, Feng Z, et al. The CRISPR/Cas9 system produces specific and homozygous targeted gene editing in rice in one generation. Plant Biotechnol J. 2014;12:797-807.

11. Zhou H, Liu B, Weeks DP, Spalding MH, Yang B. Large chromosomal deletions and heritable small genetic changes induced by CRISPR/Cas9 in rice. Nucleic Acids Res. 2014;42:10903-14.

12. Wang Y, Cheng X, Shan Q, Zhang Y, Liu J, Gao C, et al. Simultaneous editing of three homoeoalleles in hexaploid bread wheat confers heritable resistance to powdery mildew. Nat Biotech. 2014;32:947-51.

13. Arnaud N, Girin T, Sorefan K, Fuentes S, Wood TA, Lawrenson T, et al. Gibberellins control fruit patterning in Arabidopsis thaliana. Genes Dev. 2010:24:2127-32

14. Chiang H-H, Hwang I, Goodman HM. Isolation of the Arabidopsis GA4 locus. Plant Cell. 1995;7:195-201.

15. Ranford JC, Bryce JH, Morris PC. PM19, a barley (Hordeum vulgare L.) gene encoding a putative plasma membrane protein, is expressed during embryo development and dormancy. J Exp Bot. 2002:53:147-8.

16. Barrero JM, Cavanagh C, Verbyla KL, Tibbits JFG, Verbyla AP, Huang BE, et al. Transcriptomic analysis of wheat near-isogenic lines identifies PM19-A1 and A2 as candidates for a major dormancy QTL. Genome Biol. 2015;16:93.

17. Bortesi L, Fischer R. The CRISPR/Cas9 system for plant genome editing and beyond. Biotechnol Adv. 2015;33:41-52.

18. Jiang W, Zhou H, Bi H, Fromm M, Yang B, Weeks DP. Demonstration of CRISPR/Cas9/sgRNA-mediated targeted gene modification in Arabidopsis, tobacco, sorghum and rice. Nucleic Acids Res. 2013:41(20):e188.

19. Jinek M, Chylinski K, Fonfara I, Hauer M, Doudna JA, Charpentier E. A programmable dual-RNA-guided DNA Endonuclease in adaptive bacterial immunity. Science. 2012:337:816-21.

20. Hartung F, Schiemann J. Precise plant breeding using new genome editing techniques: opportunities, safety and regulation in the EU. Plant J. 2014;78:742-52.

21. Xu R-F, Li H, Qin R-Y, Li J, Qiu C-H, Yang Y-C, et al. Generation of inheritable and "transgene clean" targeted genome-modified rice in later generations using the CRISPR/Cas9 system. Sci Rep. 2015;5:11491.

22. Sparrow P, Dale P, Irwin J. Brassica oleracea. In: Wang K, editor Agrobacterium Protocols, vol. 343. New York: Humana Press; 2006. p. 417-26.
23. Mitchum MG, Yamaguchi S, Hanada A, Kuwahara A, Yoshioka Y, Kato T, et al. Distinct and overlapping roles of two gibberellin 3-oxidases in Arabidopsis development. Plant J. 2006;45:804-18.

24. Brooks C, Nekrasov V, Lippman ZB, Van Eck J. Efficient gene editing in tomato in the first generation using the clustered regularly interspaced short palindromic repeats/CRISPR-associated9 system. Plant Physiol. 2014; 166:1292-7

25. Mikami M, Toki S, Endo M. Parameters affecting frequency of CRISPR/ Cas 9 mediated targeted mutagenesis in rice. Plant Cell Rep. 2015;34:1807-15.

26. Endo M, Mikami M, Toki S. Multi-gene knockout utilizing off-target mutations of the CRISPR/Cas9 system in rice. Plant Cell Physiol. 2015:56:41-7.

27. Jiang W, Bikard D, Cox D, Zhang F, Marraffini LA. RNA-guided editing of bacterial genomes using CRISPR-Cas systems. Nat Biotech. 2013;31:233-9.

28. Cradick TJ, Fine EJ, Antico CJ, Bao G. CRISPR/Cas9 systems targeting $\beta$-globin and CCR5 genes have substantial off-target activity. Nucleic Acids Res. 2013:41:9584-92

29. Lin Y, Cradick TJ, Brown MT, Deshmukh H, Ranjan P, Sarode N, et al. CRISPR/Cas9 systems have off-target activity with insertions or deletions between target DNA and guide RNA sequences. Nucleic Acids Res. 2014:42:7473-85.

30. Fu Y, Sander JD, Reyon D, Cascio VM, Joung JK. Improving CRISPR-Cas nuclease specificity using truncated guide RNAs. Nat Biotechnol. 2014;32:279-84

31. Ran FA, Hsu Patrick D, Lin C-Y, Gootenberg Jonathan S, Konermann S, Trevino AE, et al. Double nicking by RNA-guided CRISPR Cas9 for enhanced genome editing specificity. Cell. 2013;154:1380-9.

32. Shen B, Zhang W, Zhang J, Zhou J, Wang J, Chen L, et al. Efficient genome modification by CRISPR-Cas9 nickase with minimal off-target effects. Nat Meth. 2014;11:399-402.

33. Guilinger JP, Thompson DB, Liu DR. Fusion of catalytically inactive Cas9 to Fokl nuclease improves the specificity of genome modification. Nat Biotech. 2014;32:577-82.

34. Tsai SQ, Wyvekens N, Khayter C, Foden JA, Thapar V, Reyon D, et al. Dimeric CRISPR RNA-guided Fokl nucleases for highly specific genome editing. Nat Biotech. 2014;32:569-76.

35. Borrill P, Adamski N, Uauy C. Genomics as the key to unlocking the polyploid potential of wheat. New Phytol. 2015;208:1008-22.

36. Adams KL, Wendel JF. Polyploidy and genome evolution in plants. Curr Opin Plant Biol. 2005:8:135-41.

37. The International Wheat Genome Sequencing Consortium. A chromosomebased draft sequence of the hexaploid bread wheat (Triticum aestivum) genome. Science. 2014:345:1251788.

38. Girin T, Stephenson P, Goldsack CMP, Kempin SA, Perez A, Pires N, et al. Brassicaceae INDEHISCENT genes specify valve margin cell fate and repress replum formation. Plant J. 2010;63:329-38.

39. Spence J, Vercher Y, Gates P, Harris N. 'Pod shatter' in Arabidopsis thaliana, Brassica napus and B. juncea. J Microsc. 1996;181:195-203.

40. The Brassica Database. [http://brassicadb.org/brad/blastPage.php].

41. International Barley Sequencing Consortium Database [http://webblast.ipkgatersleben.de/barley/

42. Weber E, Engler C, Gruetzner R, Werner S, Marillonnet S. A modular cloning system for standardized assembly of multigene constructs. PLoS One. 2011;6:e16765.

43. Engler $\mathrm{C}$, Youles M, Gruetzner R, Ehnert T-M, Werner S, Jones JDG, et al. A golden gate modular cloning toolbox for plants. ACS Synthetic Biol. 2014;3:839-43.

44. Harwood W. A Protocol for High-Throughput Agrobacterium-Mediated Barley Transformation. In: Henry RJ, Furtado A, editors. Cereal Genomics, vol. 1099. New York: Humana Press; 2014. p. 251-60.

45. Hundleby PAC, Irwin J. Brassica oleracea and B. napus. In: Wang K, editor Agrobacterium Protocols, vol. 1223. New York: Springer; 2015. p. 287-97.

46. Voytas DF. Plant genome engineering with sequence-specific nucleases. Annu Rev Plant Biol. 2013:64:327-50.

47. Edwards K, Johnstone C, Thompson C. A simple and rapid method for the preparation of plant genomic DNA for PCR analysis. Nucleic Acids Res. 1991;19:1349.

48. Smyth DR, Bowman JL, Meyerowitz EM. Early flower development in Arabidopsis. Plant Cell. 1990;2:755-67. 
49. Østergaard L, Kempin SA, Bies D, Klee HJ, Yanofsky MF. Pod shatter-resistant Brassica fruit produced by ectopic expression of the FRUITFULL gene. Plant Biotechnol J. 2006;:45-51.

50. Weng $H$, Pan A, Yang L, Zhang C, Liu Z, Zhang D. Estimating number of transgene copies in transgenic rapeseed by real-time PCR assay with HMG I/Y as an endogenous reference gene. Plant Mol Biol Rep. 2004;22:289-300.

Submit your next manuscript to BioMed Central and take full advantage of:

- Convenient online submission

- Thorough peer review

- No space constraints or color figure charges

- Immediate publication on acceptance

- Inclusion in PubMed, CAS, Scopus and Google Scholar

- Research which is freely available for redistribution 